TERRA. Revista de Desarrollo Local

e-ISSN: 2386-9968

Número 8 (2021), 753-758

DOI 10.7203/terra.8.20962

IIDL - Instituto Interuniversitario de Desarrollo Local

\title{
Reseña. Rural Renaissance: Derecho y medio rural
}

\section{Sergio Bellés Monserrat}

Estudiante del Programa de Desarrollo Local y Cooperación Internacional (Universidad de Valencia, España)

bemonser@alumni.uv.es

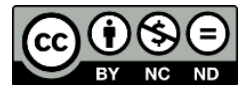

Esta obra se distribuye con la licencia Creative Commons

Reconocimiento-NoComercial-SinObraDerivada 4.0 Internacional 


\section{SECCIÓN RESEÑAS}

\section{Reseña. Rural Renaissance: Derecho y medio rural}

Resumen: El monográfico dirigido por Marcos Matías Fernando Pablo y José Luis Domínguez Álvarez recoge 17 artículos de diferentes autores cuyos vínculos con los espacios rurales son muy diversos. Resumidamente, se enuncia cómo la despoblación en las áreas rurales españolas, en general, y de Castilla y León, en particular, lleva asociadas unas causas y unas consecuencias que van más allá de lo estrictamente demográfico. A grandes rasgos, de esta obra se puede establecer que la despoblación es una problemática multicausal en la que los factores ambientales, económicos y sociales se retroalimentan, llegando a observarse, desde una escala territorial, afecciones desfavorables. Conviene destacar que se hace especial hincapié en las repercusiones positivas o negativas que, de manera más o menos directa, el Derecho y la legislación española y castellanoleonesa tienen sobre el medio rural español. En esta línea, se describen los instrumentos legislativos que, no teniendo en cuenta su distinta naturaleza territorial, o dificultan el desarrollo de las áreas rurales, o no les otorgan las suficientes ventajas comparativas, por lo que se puede afirmar que no son adecuados para tratar de fomentar su desarrollo. La obra incluye casos exitosos de desarrollo rural y algunas acciones y medidas que, desde el punto de vista legislativo, se deberían implementar para frenar el declive poblacional, primero, y tratar de revertir las dinámicas demográficas, después; por último, se hace especial referencia a la nueva realidad que la COVID19 puede provocar para los espacios rurales.

Palabras clave: Derecho, espacios rurales, declive demográfico, envejecimiento poblacional, problemática multicausal.

Recibido: 19 de mayo de 2021

Devuelto para revisión: -

Aceptado: 19 de mayo de 2021

\section{Referencia / Citation:}

Bellés, S. (2021). Reseña. Rural Renaissance: Derecho y medio rural. TERRA. Revista de Desarrollo Local, (8), 753-758. DOI 10.7203/terra.8.20962 


\title{
Marcos Matías Fernando y José Luís Domínguez (Dtors.) \\ RURAL RENAISSANCE: DERECHO Y MEDIO RURAL
}

\author{
Pamplona (España). Aranzadi, 2020, 378 páginas
}

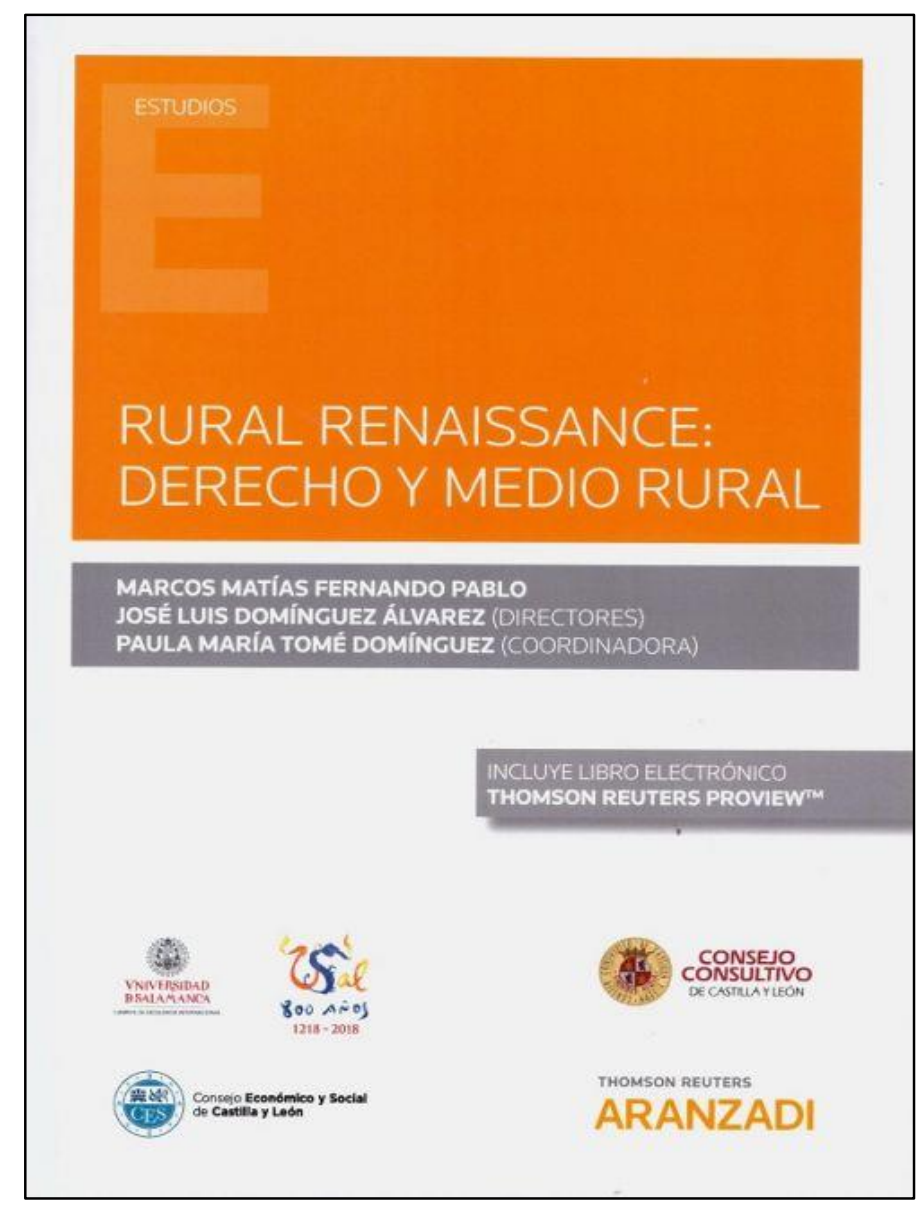

La despoblación de los espacios rurales, pese a no ser un fenómeno demográfico de afectación reciente, ha emergido con gran fuerza durante los últimos años hasta motivar su inclusión en la agenda pública y en las políticas estatales $y$ europeas.

El decrecimiento demográfico es un asunto que, pese a que muestra un mayor vigor en las áreas rurales, afecta también a los espacios urbanos. Esto se debe a que en ambos entornos se puede afirmar que existen dinámicas demográficas claramente identificables: crecimientos vegetativos negativos $\mathrm{y}$ bajas tasas de natalidad. Generalmente, en los entornos urbanos este retroceso se ve mitigado por la llegada de migrantes atraídos por su dinamismo económico, en

cambio en los entornos rurales los movimientos migratorios suelen agravar su declive poblacional, ya que quienes emigran son adultos jóvenes, lo que a medio y largo plazo favorece el envejecimiento de la población. Por tanto, se puede afirmar que el envejecimiento demográfico es un fenómeno multicausal que guarda vinculaciones directas con el declive demográfico de las áreas rurales.

A nivel español, el decrecimiento poblacional es una dinámica que se da incluso en las capitales provinciales del interior peninsular, lo que viene a mostrar la gravedad del problema. Además, se puede afirmar que se trata de un fenómeno con graves afecciones ambientales, culturales, económicas y sociales con fuertes vínculos territoriales para el cual no existen ni soluciones fáciles ni que se deban aplicar a corto plazo.

Aunque la despoblación es una dinámica que se viene dando desde antaño, ha eclosionado de manera notable, y a diferentes niveles, durante la última década en la literatura, en las políticas públicas y en la cuestión que atañe este texto: el ámbito académico.

En España, el declive poblacional de las áreas rurales es una dinámica que ha tenido diversas fases de desarrollo durante el último medio siglo. Tras la Crisis Financiera de 2008 se habla incluso de "segunda oleada de despoblación" para referirse a la aceleración de las pérdidas demográficas en las áreas rurales; estas son debidas a que, por una parte, 
perduran las emigraciones hacia las grandes ciudades y, por otra parte, al círculo vicioso de envejecimiento-baja fecundidad-baja natalidad.

\section{Figura 1. Índice de contenidos}

¡Faltan cabezas!: una nota sobre derecho público y ruralidad

Marcos Matías Fernando Pablo

El Consejo Consultivo de Castilla y León y las administraciones locales en el ámbito rural

Agustín Sánchez de Vega

La actividad agraria como sector estratégico: objetivos de desarrollo sostenible, empleo y protección social

Enrique Cabero Morán

El derecho financiero frente a la despoblación en el ámbito rural

José María Lago Montero

La custodia del territorio: régimen de un instrumento complementario del desarrollo rural

Dionisio Fernández de Gatta Sánchez

El reto demográfico desde el municipalismo. Medidas tributarias locales favorecedoras del emprendimiento y

Marcos Iglesias Caridad

¿Reinventarse o morir?. El municipalismo como piedra angular del anhelado desarrollo rural sostenible. San

Alfonso Buenaventura Calvo, José Luis Domínguez Álvarez

El destacado papel de la mujer en el desarrollo rural

María Ángeles González Bustos

La importancia de los Grupos de Acción Local para alcanzar el desarrollo rural sostenible. El caso concreto de

Juan Bautista Alonso Martín, Daniel Terrón Santos

El Estado del Bienestar en el medio rural español. La efectividad de las políticas públicas

Las organizaciones sindicales de clase también apuestan por la lucha contra la despoblación del medio rural

Óscar Moreno Corchete

¿Es posible el establecimiento de un régimen tributario favorable para el medio rural en España?

Motivos por los que los pequeños municipios son el terreno perfecto para la corrupción

Fuente: https://dialnet.unirioja.es/servlet/libro?codigo=774898. Recuperado el 19 de mayo de 2021. 
Durante los últimos 25 años, la mayor parte los municipios de menos de 20.000 habitantes han perdido población, incluidas las cabeceras comarcales, mientras que solamente han ganado habitantes las grandes ciudades y algunos núcleos urbanos de entre $20.000 \mathrm{y}$ 50.000 habitantes. Con todo se puede establecer que, en los municipios de menos de 2.000 habitantes, que representa un $55 \%$ del total y tres cuartas partes de los municipios españoles, reside únicamente el $6 \%$ de la población. Si se considera el umbral que la UE establece como de riesgo de despoblación (12,5 habitantes por kilómetro cuadrado), la mitad de los municipios españoles se encuentra en riesgo de despoblación. Si además, se hace especial atención sobre los municipios en riesgo severo de despoblación (menos de ocho habitantes por kilómetro cuadrado) los datos no sufren grandes variaciones: el $40 \%$ de los municipios españoles están en esta situación. Por tanto, es inequívoco afirmar que se trata de un problema que va más allá de lo demográfico y atañe aspectos territoriales de índole multidisciplinar que resultan ser complementarios.

Bajo el nombre de Rural Renaissance: Derecho y medio rural, este libro recoge diversos artículos que de manera sencilla, desde temáticas tan diversas como el Derecho, la Economía, la Biología y la Sociología, pretende hacer reflexionar al lector sobre los principales factores que deben ser tenidos en cuenta para describir o revertir las dinámicas demográficas negativas existentes en España, en general, y en Castilla y León en particular; de hecho, esta es una de las regiones españolas más afectadas por el declive demográfico. Se debe destacar la vigencia de esta publicación, puesto que se incluyen referencias a la crisis provocada por la pandemia de la COVID19, y la oportunidad de desarrollo y/o de cambio de paradigma que esta puede suponer, a su vez, para los espacios rurales.

A grandes rasgos, se puede establecer que los textos recogidos en los 17 capítulos de la obra: i) tratan de determinar las causas del evidente trato desigual existente entre los ciudadanos residentes en entornos rurales y en los urbanos; ii) tratan de determinar la degradación medioambiental y de biodiversidad que causa, y causará, el cese de las actividades primarias que se han llevado a cabo de manera sostenible durante siglos en estos espacios; y iii) inciden en la pérdida de oportunidad que el deficiente tratamiento que se da sobre los espacios rurales supone para otras políticas públicas (Figura 1).

Todos estos asuntos se describen prestando especial atención al ordenamiento jurídico español y castellanoleonés, tratando de analizar y conocer los mecanismos legislativos que propician o impiden el descenso poblacional.

En esta línea, se incide de manera especial en aquellos cambios legislativos recientes que resultan ser muy favorables para combatir esta problemática y, especialmente, en aquellos que, a criterio de cada uno de los autores de la obra, se deberían implementar y/o trasladar a otras regiones con características similares.

En relación al contenido de la obra, se puede observar cómo se incide en el papel que juega el derecho en todas sus ramas en los espacios rurales, y la necesidad de un tratamiento jurídico y tributario particular desde el ámbito normativo, con el objetivo de lograr actuaciones directas diferenciadas sobre los municipios rurales. La mayor parte de las aportaciones se centran en el caso castellanoleonés, y más concretamente en el consejo consultivo, un órgano exclusivo de esta autonomía. El análisis de los contenidos legislativos presta especial atención al crecimiento de iniciativas desde la base, de modo que se establecen vinculaciones con actividades que han contado, y cuentan, con una gran relevancia en los espacios rurales españoles. De este modo, sobresale el papel del ámbito municipal en el desarrollo de los espacios rurales y en los mecanismos legislativos de los que se dispone, puesto que son estos los organismos con contacto más directo con los 
vecinos. En esta línea se describen ejemplos de municipios castellanoleoneses que, conociendo su potencial y sus limitaciones, han sabido adaptarse y han hecho del turismo y otras actividades vinculadas a este sector, su principal motor económico; también se indica que, debido a la organización político-social, la escala municipal es susceptible de ser más fácilmente influida por interés particulares y, con ello, imposibilitar el correcto desarrollo del municipio.

También se hace referencia a nuevos usos territoriales y consideraciones socioeconómicas que deben ser tenidas en cuenta por su gran potencial dinamizador: la custodia del territorio, el destacado y olvidado papel de las mujeres en el desarrollo rural, el papel de los sindicatos agrarios, y el potencial que deriva de los movimientos colaborativos y el entramado de la innovación y la economía social.

Como ultima consideración, se enuncia la vinculación de los espacios rurales con la administración pública. También se indica la ineficacia de la adopción de medidas de manera homogénea para todo el territorio, y del agotamiento resultante de la no realización de distinciones para espacios rurales. Todo eso sirve para tratar de determinar si existe vinculación directa, o no, con la deficiente prestación de servicios existente en los espacios rurales y el declive poblacional; en esta línea se establecen un mínimo de servicios públicos que deberían contar todos los municipios, sin distinción de su tamaño demográfico, lo que supondría una primera motivación para no emigrar.

Por tanto, teniendo en consideración todos los instrumentos legislativos vigentes en España, en general, y Castilla y León, en particular, se indican los problemas existentes en los entornos rurales que la legislación actual no es capaz de resolver, las oportunidades que ofrece, y ofrecería, un tratamiento normativo diferenciado que revalorizase los territorios rurales, y la necesidad de contar con una discriminación jurídica positiva para los habitantes de estos espacios.

Sergio Bellés Monserrat Graduado en Geografía y Medio Ambiente, Universidad de Valencia (España) 